\title{
Health care problems of lesbian, gay, bisexual, and transgender patients
}

About $10 \%$ of the population is lesbian, gay, bisexual, or transgender. ${ }^{1,2}$ These people face health care risks that are often not addressed because of lack of knowledge of the patient's sexual orientation, ignorance of specific health care issues, or because the patient feels that the health care professional is homophobic. The goals of this article are to educate health care professionals on specific health care issues faced by this community.

Only a limited amount of information is available on health care risks within the lesbian, gay, bisexual, or transgender population. Most studies do not address sexual orientation. Fear of stigmatization prevents many people from identifying themselves as lesbian, gay, bisexual, or transgender. In addition, many do not seek health care (and are therefore excluded from health studies) because of prior negative experience. As many as two thirds of physicians never ask patients about their sexual orientation. ${ }^{3}$ Some health care professionals assume that their patients are heterosexual. Others may be homophobic and hostile and prefer to avoid the issue.

\section{METHODS}

A MEDLINE search was conducted using "homosexuality" paired with specific health care terms such as "substance abuse," "breast cancer," "cervical cancer," and "suicide." Because of the paucity of research on the specific health care issues facing the lesbian, gay, bisexual, and transgender population (except for human immunodeficiency virus [HIV] infection or acquired immunodeficiency syndrome in homosexual men), the search was conducted on 1980 to current databases.

\section{As many as two thirds of physicians} never ask patients about their sexual

\section{orientation}

\section{HEALTH RISKS Depression and suicide}

In the controversial report of the Secretary of the Department of Health and Human Services, Task Force on Youth Suicide in 1989, Gibson estimated that gay youths account for $30 \%$ of completed suicides. ${ }^{4}$ Forty percent of

\section{Summary points}

- Lesbian, gay, bisexual, and transgender patients are at increased risk of suicide, eating disorders, substance misuse, and breast and anal cancer

- Fear and lack of knowledge by both providers and patients can lead to suboptimal or no provision of health care

- Practitioners need to improve awareness and take steps to create an open, nonhostile environment

- Community outreach, education, and research are necessary to attain optimum health care for this population

lesbian, gay, bisexual, or transgender youth have either attempted or seriously contemplated suicide. Gay men are 6 times more likely to attempt suicide than their heterosexual counterparts; lesbians are twice as likely to attempt suicide as heterosexual women. ${ }^{4}$ In general, suicide attempts by gay men are more severe than those of their heterosexual counterparts. ${ }^{5}$ Risk factors associated with an increased likelihood of suicide attempts included nonconforming to gender (for example, men in more feminine gender roles), self-identification as gay or bisexual at a young age, first homosexual experience at an early age, history of sexual or physical abuse, and rejection from important social supports. ${ }^{5,6}$

Adults are also at risk. Some people do not realize their sexual orientation until adulthood and face social isolation, fear of discrimination at work, and loss of loved ones. Suicide prevention awareness and intervention (table) have been shown to decrease the number of suicide attempts and completions. ${ }^{7}$

\section{Substance misuse}

Early reports on drug and alcohol use in the lesbian, gay, bisexual, and transgender community suggested that substance abuse affected about a third of the adult gay population (L H Fifield, J D Lathan, C Phillips, "Alcoholism in the Gay Community: the Price of Alienation, Isolation, and Oppression," a project of the Gay Community Services Center, Los Angeles, 1977). More recent population-based surveys found few differences in drinking patterns and frequency of drug misuse between homosexual and heterosexual men. ${ }^{8}$ Comparisons of lesbian and heterosexual women showed no differences in
Rita Lee

Internal Medicine Residency Program Cleveland Clinic Foundation 9500 Euclid Ave, Mailcode NA-21 Cleveland, OH 44195

Correspondence to: Dr Lee ritalee69@hotmail.com Competing interests: None declared

West J Med 2000;172:403-408 


\begin{tabular}{|c|c|}
\hline \multicolumn{2}{|c|}{ Suicide prevention techniques } \\
\hline Warning signs of suicide & $\begin{array}{l}\text { - Changes in eating or sleeping habits } \\
\text { - Increasing isolation from family and friends } \\
\text { - Tendency to become more active and aggressive than usual } \\
\text { - Lower academic grades } \\
\text { - Giving away valued possessions and/or increased interest in getting "life in order" } \\
\text { - Talking about or threatening suicide } \\
\text { - Sudden and intense interest in religious beliefs and the afterlife } \\
\text { - Experiencing recent loss, such as death of a loved one, or a close friend moving away } \\
\text { - Misuse of drugs and/or alcohol }\end{array}$ \\
\hline Suicide prevention & $\begin{array}{l}\text { - Provide counsel, and, if possible, resolve the problem or reduce the level of stress experienced } \\
\text { - Meet on a regular basis to provide active support } \\
\text { - Refer to community support groups as needed } \\
\text { provide a list of community agencies/providers if mental health services are needed. Ensure that these } \\
\text { professionals are supportive of lesbian, gay, bisexual, and transgender population }\end{array}$ \\
\hline Imminent suicide & $\begin{array}{l}\text { - Activate emergency medical system (call 911) in a life-threatening emergency } \\
\text { - Notify the parents, unless they are suspected to be the reason for the youth's actions } \\
\text { - Provide and maintain constant professional supervision } \\
\text { - Provide the youth and his/her parents with a list of community resources (crisis centers, mental health } \\
\text { clinic, hospital, etc) }\end{array}$ \\
\hline
\end{tabular}

alcohol consumption, although lesbians and bisexual women were more likely to report being recovering alcoholics. ${ }^{9,10}$

Gay men use a wider variety of drugs, such as marijuana, "poppers" (amyl nitrite or butyl nitrite), methylenedioxyamphetamine (MDA), barbiturates, ethyl chloride, and amphetamines. ${ }^{8}$ Although causality cannot be determined, a history of consistent use of inhalants, amphetamines, and cocaine is strongly associated with HIV seroconversion, independent of injection drug use. ${ }^{11}$

About $35 \%$ of gay men and $38 \%$ to $43 \%$ of lesbians reported smoking cigarettes in the past month. This exceeds national averages found in the 1990 National Household Survey on Drug Abuse, which reported current cigarette smoking in $27 \%$ of men and $22 \%$ of women. ${ }^{12}$ Health care professionals should actively assess the extent and context of substance misuse in their lesbian, gay, bisexual, and transgender patients. Patients should be referred to treatment and support groups (see box p 405) that are sensitive to this population.

\section{Antigay violence}

In 41 of 50 states, discriminating against an employeefiring or refusing to hire-based solely on his or her sexual orientation is still legal (www.ngltf.org). In addition, most states do not include sexual orientation under hate crime laws.

In an environment that offers little protection and an abundance of homophobic sentiment, many people are subject to antigay violence and harassment. In a survey of college students and faculty at Yale University, 65\% of the lesbian, gay, bisexual, and transgender population had ex- perienced verbal insults. A fourth were threatened with physical violence. ${ }^{13}$

Health care professionals should create a safe, nonjudgmental environment for battered patients - such as posting sticker-notices to indicate safe zones for the lesbian, gay, bisexual, and transgender population-and take an active role in stopping the perpetration of antigay sentiment among colleagues. In addition, professionals should be aware of community support systems within schools and workplaces.

\section{PROBLEMS OF YOUTH \\ School-related problems}

More than 95\% of lesbian, gay, bisexual, and transgender youth feel separated and emotionally isolated from their peers because they feel different. Almost half of gay youth and $20 \%$ of lesbians are verbally or physically assaulted in secondary school. ${ }^{4}$ Lesbian, gay, bisexual, and transgender youth are 4 times more likely to be threatened with a weapon on school property than their heterosexual counterparts. ${ }^{14}$ Lesbian, gay, bisexual, and transgender youth are 5 times more likely to miss school for fear of their personal safety; $28 \%$ of these students drop out of high school. ${ }^{14,15}$

\section{Substance misuse}

Nearly $60 \%$ of bisexual and gay male youths in 1 study were currently using substances and met psychiatric criteria for substance misuse. ${ }^{16}$ Lesbian, gay, bisexual, and transgender youths are 9 times more likely to use injectable drugs. They also are more likely to engage in sexual 


\section{Lesbian, gay, bisexual, and transgender resources}

\section{General}

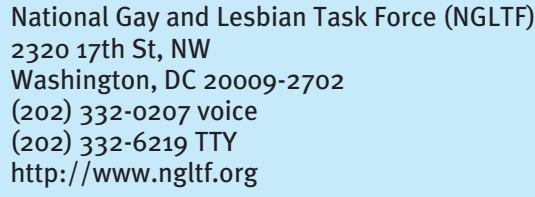

National Gay and Lesbian Task Force (NGLTF)

232017 th St, NW

Washington, DC 20009-2702

(202) 332-0207 voice

(202) 332-6219 TTY

http://www.ngltf.org

\section{National Black Lesbian and Gay Leadership Forum (NBLGLF) \\ 1612 K St, NW Suite 500 \\ Washington, DC 20006 \\ (202) 483-6786 \\ e-mail: nblglf@nblglf.org \\ http://www.nblglf.org}

\author{
Federation of Parents and Friends of Lesbians and Gays \\ (PFLAG) \\ 1101 14th Street, NW, Suite 1030 \\ Washington, DC 20005 \\ (202) 638-4200 \\ http://www.pflag.com
}

Bisexual Resource Center (BRC)

PO Box 639

Cambridge, MA 02140

(617) 424-9595

e-mail: brc@biresource.org

http://www.biresource.org

Renaissance Transgender Association

987 Old Eagle School Rd, Suite 719

Wayne, PA 15087

(610) 975-9119

e-mail: info@ren.org

http://www.ren.org

\section{Straight But Not Narrow}

PO Box 71202

Marietta, CA 30007

(770) $242-2256$

e-mail: sbnn@mindspring.com

http://dislecksea.home.mindspring.com/sbnn.html

Gay and Lesbian National Hotline

(888) $843-4564$

http://glnh.org

National Latino/a Lesbian, Gay, Bisexual, and Transgender Organization (LLEGO)

1612 K Street, Suite 500

Washington, DC 20006

AquiLGBT@LLEGO.org

http://www.llego.org

\section{Professional organizations}

Gay and Lesbian Medical Association (GLMA)

459 Fulton St, Suite 107

San Francisco, CA 94102

(415) 255-4547

e-mail: info@glma.org

http://glma.org/indexmain.html

Lesbian, Gay, and Bisexual People in Medicine

Committee of the American Medical Students Association

(LGBPM-AMSA)

1902 Association Dr

Reston, VA 20191

Contact: Ruth Michaelis

(703) 620-6600, ext 458

e-mail: rmichaelis@siumed.edu

http://www.amsa.org/sc/lgbpm.html

Association of Gay and Lesbian Psychiatrists (AGLP)

4514 Chester Ave

Philadelphia, PA 19143-3707

(215) 222-2800

e-mail: aglpnat@aol.com

http://members.aol.com/aglpnat/homepage.html

Youth and community resources

!OutProud! The National Coalition for Gay, Lesbian,

Bisexual, Transgender Youths

369 Third St, Suite B-362

San Rafael, CA 94901-3581

e-mail: info@outproud.org

http://www.outproud.org

Advocates for Youth

1025 Vermont Ave, NW, Suite 200

Washington, DC 20005

(202) 347-5700

e-mail:info@advocatesforyouth.org

http://www.youthresource.com

National Directory of Lesbian and Gay

Community Centers

One Little West 12th St

New York, NY 10014

(212) 620-7310

e-mail: webmaster@gaycenter.org

http://www.gaycenter.org/natctr

Youth Assistance Organization

e-mail: webmaster@youth.org

http://www.youth.org activity, use cocaine, and smoke marijuana and tobacco before age $13 .{ }^{17}$

\section{Suicide}

It is estimated that lesbian, gay, bisexual, and transgender adolescents are 3 times more likely to attempt suicide than their heterosexual counterparts. ${ }^{14}$ Of those who are homeless, about half have attempted suicide at least once. ${ }^{18}$

\section{Homelessness}

Many lesbian, gay, bisexual, and transgender youth leave their home because of stresses in the family environment or because they are thrown out by homophobic parents. ${ }^{19}$ Many foster homes will not accept openly gay, lesbian, bisexual, or transgender youth because of homophobia and fear of predation on other children in the home. About $6 \%$ of all runaway youth identify themselves as gay 
or lesbian. ${ }^{18}$ In certain locales, lesbian, gay, bisexual, and transgender youths make up a much larger percentage of runaways: $40 \%$ of street youths in Seattle and 30\% of runaway youths in Los Angeles. ${ }^{15}$

\section{Antigay violence}

In a study of lesbian, gay, bisexual, or transgender youth, $40 \%$ had experienced violent physical attacks. The Massachusetts Governor's Commission on Gay and Lesbian Youth in their 1993 education report cited numerous anecdotes of physical assaults by both peers and family members. $^{15}$

\section{Prostitution}

Many lesbian, gay, bisexual, and transgender youth have low self-esteem and resort to prostitution to survive and to escape physical, sexual, and emotional abuse in their homes and schools. On the street, they are victims of rape, exploitation, drug misuse, and at risk of contracting HIV. ${ }^{17}$

\section{Health care professionals should} take a detailed sexual history, including the number and sex of previous partners, specific activities engaged in, and the use of preventive

\section{measures}

\section{LESBIAN HEALTH Cervical cancer}

In a recent national survey, only $54 \%$ of lesbian and bisexual women had been given a cervical smear within the past year, and $7.5 \%$ had never had a Papanicolaou smear. ${ }^{20}$ This is partially due to the misconception of both lesbians and health care professionals that lesbians are not at risk of cervical cancer. ${ }^{21}$ In one study, $30 \%$ of lesbians and bisexual women had a history of sexually transmitted diseases. ${ }^{22}$ There are several case reports of cervical intraepithelial neoplasia and infection with human papillomavirus in women who admit to sexual activity only with women. ${ }^{23,24}$ In one study of women with no history of sex with men, $14 \%$ had cervical intraepithelial lesions. ${ }^{25}$ Sexually contracted diseases are thought to be transmitted through vaginal secretions and possibly fomites, such as sex toys. ${ }^{23,26}$ Physicians should recommend cervical screening according to current guidelines and teach safe sex techniques to prevent the transmission of human papillomavirus between sexual partners.

\section{Breast and endometrial cancer}

Lesbian and bisexual women are less likely to use oral contraceptives, more likely to be nulliparous, and more likely to smoke cigarettes than heterosexual women-all risk factors for breast and endometrial cancer., ${ }^{9,27}$ Studies on the number of lesbian and bisexual women having mammography compared with heterosexual women are contradictory, with 1 national survey showing the former population more likely to have mammography_although most respondents were white and well educated ${ }^{20}$ - and others showing they are less likely to either have mammography or examine their own breasts. ${ }^{27}$ Health care professionals should recommend annual screening according to guidelines. They should also be aware of local support groups for lesbians with breast cancer.

\section{Sexually transmitted diseases}

Recent evidence suggests that it is possible to transmit diseases from woman to woman through sexual activity. ${ }^{23}$ Although there is no clear evidence of woman-to-woman transmission of HIV, several cases have been reported where the only known risk factor was sexual contact with a woman. ${ }^{26}$ The virus has been detected in cervical and vaginal secretions throughout the menstrual cycle. Sexual behaviors thought to be associated with increased risk of transmission include vaginal-vaginal contact, cunnilingus, anilingus, digital or manual vaginal or anal contact, and insertion of sexual devices or toys into the mouth, vagina, or anus. Sex toys such as dildos, vibrators, and analinsertive devices may cause trauma and increase the risk of HIV transmission. The sharing of toys without disinfection between partners may allow exchange of infected fluids. ${ }^{26}$ Unprotected oral-genital contact can lead to oropharyngeal carriage of gonorrhea. Oral-anal intercourse may transmit gastrointestinal infections such as Giardia Lamblia and Entamoeba histolytica. ${ }^{28}$

Health care professionals should take a detailed sexual history, including the number and sex of previous partners, specific activities engaged in, and the use of preventive measures such as condoms, gloves, and dental dams. Practitioners should educate their lesbian and bisexual female patients on the risks of sexually transmitted diseases and the proper use of protective barriers.

\section{GAY MALE HEALTH Eating disorders}

Gay men have higher rates of dieting and binge eating than heterosexual men. ${ }^{29}$ One study found that clinical 
eating disorders could be diagnosed in $17 \%$ of gay men, $14 \%$ of heterosexual women, $4.2 \%$ of lesbians, and $3.4 \%$ of heterosexual men surveyed. ${ }^{30}$ Health care professionals should refer patients with eating disorders to community groups and specialists who are sensitive to gay issues.

\section{Sexually transmitted diseases}

The association between anal-receptive intercourse and increased risk of HIV transmission has long been established and is thought to be due to HIV entrance at points of mucosal trauma. ${ }^{26}$ Anal-receptive intercourse is associated with an increased risk of infection with HIV, human papillomavirus, hepatitis B virus, and herpesvirus. Anal- and oral-insertive (during fellatio) intercourse is strongly associated with urethritis, including gonococcal and chlamydial infection. Oral-receptive intercourse increases the risk of HIV and pharyngeal gonorrhea infection. ${ }^{31}$ Oral-anal intercourse may lead to gastrointestinal infection caused by organisms such as $G$ lamblia; $E$ histolytica; Shigella, Salmonella, and Campylobacter species; and hepatitis A virus. $^{28}$

Because each sexual behavior carries a separate risk of transmitting disease, health care professionals must assess sexual activity. Physicians must also assess the competency of their patients to use preventive measures. One study of gay men found that more than $80 \%$ of them did not know how to use condoms appropriately. ${ }^{32}$

\section{Anal cancer}

The risk factors for the development of anal cancer are a history of anal-receptive intercourse; history of genital warts; herpes simplex virus, type 2 , infection; hepatitis $B$ virus infection; history of chlamydial infection; and being a current smoker. ${ }^{33}$

Patients who practice anal-receptive intercourse and are infected with HIV have a greater risk of developing highgrade anal intraepithelial neoplasia and anal cancer. ${ }^{34}$ Physicians should examine the anal area of patients practicing anal intercourse and search for predisposing diseases and anal cancer. ${ }^{35}$

\section{TRANSGENDER HEALTH}

Transgender persons are those who maintain a strong and persistent cross-gender identification, not merely a desire for any cultural advantages of being the other sex. Transgender persons are considered by the American Psychiatric Association to have gender identity disorder. Those who are transgender (transsexual) face even greater challenges than lesbians, gays, and bisexuals. They are a minority within a minority group. Therefore, they may be at greater risk for depression, suicide, substance abuse, and antigay violence, although this has not been studied.
Transsexuals may seek gender reassignment surgery. The process of gender reassignment is long and involves psychiatric, endocrinologic, and surgical evaluation. People begin hormone therapy before any surgical procedure. In addition to the risk of thromboembolism and liver abnormalities with estrogen use, there is also the rare possibility of pituitary prolactinoma developing. ${ }^{36}$ For female-to-male transgender persons, androgen therapy carries an increased risk for heart disease, endometrial hyperplasia, and subsequent endometrial carcinoma. ${ }^{37}$

\section{One study of gay men found that more than $80 \%$ of them did not know}

\section{how to use condoms appropriately}

Gender reassignment surgery may cause sexual dysfunction, especially with sexual responsivity. ${ }^{38}$ In addition, although the neovagina in male-to-female transsexuals is relatively resistant to infection, cases of gonococcal urethritis and vaginitis have been reported. ${ }^{39}$ Those who use hormone therapy but decide not to undergo surgery continue to be at risk for endometrial cancer (female-tomale persons) and prostate cancer (male-to-female persons). 37,40

Physicians need to be especially sensitive to the psychosocial and medical status of their transgender patients. Some patients choose to be called by a name that may conform more to their ideal gender.

\section{CONCLUSIONS}

Lesbian, gay, bisexual, and transgender persons face unique health care risks. Further research is needed to fully evaluate the health care issues facing this population. Community outreach is needed to educate people on their health risks, the need for screening, and preventive measures.

Dr Lee is a resident in internal medicine at the Cleveland Clinic Foundation. She plans to practice general internal medicine with an emphasis on lesbian, gay, bisexual, and transgender health.

References

1 Kinsey AC, Pomeroy W, Martin C. Sexual Behavior in the Human Male. Philadelphia: WB Saunders; 1948.

2 Kinsey AC, Pomeroy W, Martin CE, et al. Sexual Behavior in the Human Female. Philadelphia: WB Saunders; 1953.

3 Allen LB, Glicken AD, Beach RK, et al. Adolescent health care experience of gay, lesbian, and bisexual young adults. $J$ Adolesc Health 1998;23:212-220.

4 Gibson P. Gay male and lesbian youth suicide. In: Remafedi G, ed. Death by Denial: Studies of Suicide in Gay and Lesbian Teens. Boston: Alyson Publications; 1994:15-88. 
5 Remafedi G, Farrow JA, Deisher RW. Risk factors for attempted suicide in gay and bisexual youth. Pediatrics 1991;87:869-875.

6 Schneider SG, Farberow NL, Kruks GN. Suicidal behavior in adolescent and young adult gay men. Suicide Life Threat Behav 1989;19:381-394.

7 Zenere FJ 3rd, Lazarus PJ. The decline of youth suicidal behavior in an urban, multicultural public school system following the introduction of a suicide prevention and intervention program. Suicide Life Threat Behav 1997;27:387-402.

8 Stall R, Wiley J. A comparison of alcohol and drug use patterns of homosexual and heterosexual men: the San Francisco Men's Health Study. Drug Alcohol Depend 1988;22:63-73.

9 Welch S, Howden-Chapman P, Collings SC. Survey of drug and alcohol use by lesbian women in New Zealand. Addict Behav 1998;23:543-548.

10 Bloomfield K. A comparison of alcohol consumption between lesbians and heterosexual women in an urban population. Drug Alcohol Depend 1993;33:257-269.

11 Chesney MA, Barrett DC, Stall R. Histories of substance use and risk behavior: precursors to HIV seroconversion in homosexual men. $\mathrm{Am} \mathrm{J}$ Public Health 1998;88:113-116.

12 Skinner WF. The prevalence and demographic predictors of illicit and licit drug use among lesbians and gay men. Am J Public Health 1994;84:1307-1310.

13 Herek GM. Documenting prejudice against lesbians and gay men on campus: the Yale Sexual Orientation Survey. J Homosex 1993;25:15-30

14 Garofalo R, Wolf RC, Kessel S, et al. The association between health risk behaviors and sexual orientation among a school-based sample of adolescents. Pediatrics 1998;101:895-902.

15 The Massachusetts Governor's Commission on Gay and Lesbian Youth. Making schools safe for gay and lesbian youth: breaking the silence in schools and families. In: Remafedi G, ed. Death by Denial: Studies of Suicide in Gay and Lesbian Teens. Boston: Alyson Publications; 1994:151-205.

16 Remafedi G. Adolescent homosexuality: psychosocial and medical implications. Pediatrics 1987;79:331-337.

17 Savin-Williams RC. Verbal and physical abuse as stressors in the lives of lesbian, gay male, and bisexual youths: associations with school problems, running away, substance abuse, prostitution, and suicide. $J$ Consult Clin Psychol 1994;62:261-269.

18 Kruks G. Gay and lesbian homeless/street youth: special issues and concerns. I Adolesc Health 1991;12:515-518.

19 Boxer AM, Cohler BJ, Herdt G, et al. Gay and lesbian youth. In: Tolan PH, Cohler BJ, eds. Handbook of Clinical Research and Practice With Adolescents. New York: Wiley; 1993:249-280.

20 Diamant AL, Shuster MA, Lever J, et al. Lesbian and bisexual women: receipt of preventive health care services. Abstr Book Assoc Health Serv Res 1997;14:266.

21 Price JH, Easton AN, Telljohann SK, et al. Perceptions of cervical cancer and pap smear screening behavior by women's sexual orientation. J Community Health 1996;21:89-105.

22 Rankow EJ, Tessaro I. Cervical cancer risk and Papanicolaou screening in a sample of lesbian and bisexual women. J Fam Pract 1998;47:139-143.
23 Ferris DG, Batish S, Wright TC, et al. A neglected lesbian health concern: cervical neoplasia. J Fam Pract 1996;43:581-584.

24 O'Hanlan KA, Crum CP. Human papillomavirus-associated cervical intraepithelial neoplasia following lesbian sex. Obstet Gynecol 1996;88(pt 2):702-703

25 Marrazzo JM, Koutsky LA, Stine KL, et al. Genital human papillomavirus infection in women who have sex with women. J Infect Dis 1998;178:1604-1609.

26 White JC. HIV risk assessment and prevention in lesbians and women who have sex with women: practical information for clinicians. Health Care Women Int 1997;18:127-138.

27 Rankow EJ. Breast and cervical cancer among lesbians. Womens Health Issues 1995; 5:123-129.

28 Harrison AE. Primary care of lesbian and gay patients: Educating ourselves and our students. Fam Med 1996;28:10-23.

29 French SA, Story M, Remafedi G, et al. Sexual orientation and prevalence of body dissatisfaction and eating disordered behaviors: a population-based study of adolescents. Int J Eat Disord 1996;19:119-126.

30 Siever MD. Sexual orientation and gender as factors in socioculturally acquired vulnerability to body dissatisfaction and eating disorders. $J$ Consult Clin Psychol 1994;62:252-260.

31 Lafferty WE, Hughes JP, Handsfield HH. Sexually transmitted diseases in men who have sex with men: acquisition of gonorrhea and nongonococcal urethritis by fellatio and implications for STD/HIV prevention. Sex Transm Dis 1997;24:272-278.

32 Martin DJ. A study of the deficiencies in the condom-use skills of gay men. Public Health Rep 1990;105:639-640.

33 Daling JR, Weiss NS, Hislop TG, et al. Sexual practices, sexually transmitted diseases, and the incidence of anal cancer. $N$ Engl J Med 1987;317:973-977.

34 Surawicz CM, Critchlow C, Sayer J, et al. High grade anal dysplasia in visually normal mucosa in homosexual men: seven cases. $\mathrm{Am} \mathrm{J}$ Gastroenterol 1995;90:1776-1778.

35 Palefsky JM, Holly EA, Hogeboom CJ, et al. Anal cytology as a screening tool for anal squamous intraepithelial lesions. J Acquir Immune Defic Syndr Hum Retrovirol 1997;14:415-422.

36 Kovacs K, Stefaneanu L, Ezzat S, et al. Prolactin-producing pituitary adenoma in a male-to-female transsexual patient with protracted estrogen administration: a morphologic study. Arch Pathol Lab Med 1994;118:562-565.

37 Futterweit W. Endocrine therapy of transsexualism and potential complications of long-term treatment. Arch Sex Behav 1998;27:209-226

38 Green R. Sexual functioning in post-operative transsexuals: male-to-female and female-to-male. Int J Impot Res 1998;10(supp 1):S22-S24.

39 Bodsworth NJ, Price R, Davies SC. Gonococcal infection of the neovagina in a male-to-female transsexual. Sex Transm Dis $1994 ; 21: 211-212$

40 Thurston AV. Carcinoma of the prostate in a transsexual. Br J Urol 1994;73:217.

\section{The Challenge of Preventive Medicine in the Year 2000}

"We are under no illusion that preventive strategies will be easy to implement. For a start, the costs of prevention have to be paid in the present, while its benefits lie in the distant future. And the benefits are not tangible-when prevention succeeds, nothing happens. Taking such a political risk when there are few obvious rewards requires conviction and considerable vision."

K Annan, Secretary General of the United Nations ${ }^{1}$

1 Annan K. Preventing conflict in the next century. In: Fishburn D, ed. The World in 2000. London: Economist Publications, $1999: 91$. 